\title{
Management and Evaluation of Communication and Coordination Practices among Multi Stakeholders in Complex Engineering Projects in Pakistan
}

\author{
Kamran Siddique (MS-Civil Engineering), \\ Department of Civil Engineering, IQRA National University \\ Engr. M. Zeeshan Ahad (MS-Construction Project \\ Management), \\ Chairman/Assistant Professor, Department of Civil Engineering, IQRA \\ National University \\ Wasim Ud Din (MS-Finance), \\ Department of Management Sciences, Comsats University Islamabad
}

Doi: 10.19044/esj.2019.v15n3p354 URL:http://dx.doi.org/10.19044/esj.2019.v15n3p354

\begin{abstract}
The aim of this study is to investigate the management and evaluation of communication and coordination practices among multi stakeholders in complex engineering projects in Pakistan. The methodology of this study is based on questionnaire to calculate the vested interest-impact index (ViII), Position (Pos), Attributes (A), Shareholder Impact Index (SII), Normalize score of SII and ranking of normalize score of SII. In addition, this study also used the Stakeholder Impact/Probability matrix. There are 44 questions asked from 132 respondents. The result reveal that different stakeholders showed interests in construction projects, however, every stakeholder had their own agenda and interest which create a conflict. Stakeholders' impact index and probability impact matrix approach for assessment of current practice and their requirements for coordination and communication have been used. Study also represents the class and position of stakeholders during both phases. As per results, land owners have high and positive impact on complex projects throughout the project life cycle followed by local community/residents, media, institutional forces and politicians. The politicians have highest positive impact on complex projects followed by consultant, main contractor and government agencies. Efficient communication and coordination is required with low impact stakeholders for minimizing their influence. It is observed that the high value of ViII will lead to higher value of SII and normalize score of project's PP and EP. The top five stakeholders are clients, consultants, main contractors, sub-contractors and government agencies in
\end{abstract}


project's planning and execution phase. The shareholder impact analysis also provides suggestions to project managers in developing and evaluating the stakeholder management process. The proposed study is first approach towards communication and coordination management in construction. Overall, the results show that since there is no contractual binding between external stakeholders and project sponsors, they face the maximum communication gap. There is no proper mean to establish coordination and communication among external stakeholders throughout the project.

Keywords: Stakeholders, Coordination, Construction Engineering, Assessment, Vested Interest Impact Index (ViII), Shareholder Impact Index (SII)

\section{Introduction}

The construction industry encompasses diversity of projects and every construction project (CP) has its own way of involving myriads of interrelated endeavors, ventures, tasks and work packages. Considering these complexities, construction is regarded as an unfavorable and always at odds with business in observance with other industries. Therefore, CP usually falls off with clefts and fissures in the matter of voluminous waste, meager yields, cost and time overruns and a continuous struggle with competition around conflicts and disputes within (Zeng et al., 2005). The construction industry contributes dynamically in the socio-economic development of a country always paving a step forward. The core objectives of socio economic progress are infrastructure, sanctuary and employment (Khan, 2008). In developing countries, almost $85.4 \%$ of the world's population are resides and government can plan and implement mega construction projects which are too complex and unique in their nature in order to achieve development (Cohen, 2006). Therefore, the targets are achieved through constructing infrastructure such as residential schemes, hospitals, schools, townships, roads, railways, highways, airports, dams, seaports, power systems, irrigation and agriculture systems and telecommunications etc. to meet the needs of societies and come to term with their demands.

There are great number of stakeholders in construction industry. This involvement of multitude stakeholders, common to construction industry in comparison with other industries, has resulted in conceptual fragmentation. Despite this fragmentation, the construction industry actualizes complex projects but with certain limitations. These limitations can be significantly attributed to the struggle faced while bringing about level of coordination and communication necessary for delivering any project efficiently. CP affects stakeholders positively as well as negatively. The favorable complying effects can be; better communication, improved coordination, exceedingly superior 
housing or desirably surpassed standards of living. The most common negative resultant of a $\mathrm{CP}$ is worsening and deterioration of the environment in physical terms for the stakeholders involved (Olander, 2002). The demands vary with different stakeholder groups. A CP might be beneficial and productive to one stakeholder group while negatively impacting the other. To build relationships it is necessary to understand each other's point of view, thus averting intolerant and predetermined opinions (Watson et al., 2002). Therefore, analyzing the diversity of demands put forward by different stakeholders must be done in project management for the facilitation of Communication and Coordination (C\&C) among them.

Relationship management is subjected to betterment of $\mathrm{C} \& \mathrm{C}$ among stakeholders which is an effective approach to lessen the potential delays (Meng, 2012). Coordination is actually a well-planned and organized way of managing resources so that a surpassing standard of operational efficiency might be actualized in any given project (Hossain, 2009). Communication is a process through which one party tries to deliver a message for better understanding. It is a way of conveying information among different sources. Project success with regards to cost and time measure, quantity vs quality as well as well-being and security is factually poor in construction industry. Complexity of design and construction process often leads to poor performance of project. However, the ability to judge the complexity at the very beginning during initial stage of a project would result in better more valuable understanding of the project as well as the stakeholders involved and hence holds great importance in successful management of projects together with a marked reduction in the associated risks. In any project, be in $\mathrm{CP}$ or other fields, diverse and most often discrepant interests should be highlighted and considered. Community requirements put pressure on organizations for devising new methodology to carry out work and enhance communication among stakeholders. A negative viewpoint of stakeholders can severely cause hindrance to construction's complex project. Unsatisfactory and poor management of the apprehensions of stakeholders are the cause of controversial issues regarding execution of $\mathrm{CP}$.

It is distinguishing that construction industry of Pakistan is hazardous and poor in terms of $\mathrm{C} \& \mathrm{C}$ practices among stakeholders. Due to poor management practices followed in C\&C among variable stakeholders, it results in time and cost overruns and sometimes the execution is not even implemented. This study is aimed at finding and identifying which stakeholder needs more coordination and communication at different phases of complex projects and to find their implications at each phase.

Stakeholder theory mainly urges that the managers are to line up the official welfares of peoples and groups which are affecting or being affected by activities of their organization (Donaldson and Preston, 1995; Freeman, 
1984). But Stakeholder theory mainly unfolds current situations and it owns a managerial feature because of its ability to predict the cause-effect linkages. In addition, stakeholders are recognized despite their fluctuating involvement in activities of business and decisions taken at any stage (Donaldson and Preston, 1995). The cause-effect linkages are obvious in construction projects throughout the project life cycle (PLC). Some stakeholders are ignored at design stage that are causing the conflicts in construction and will lead to financial loss. The linkages between attention to stakeholder's interests and related activities is one of the core feature of stakeholder theory from a managerial point of view as it can support the role of managers to achieve corporate goals (Malkat and Byung-Gyoo, 2012). The objective of this article is to identify the key stakeholder requiring more coordination and communication in project's planning and execution phase. In addition, the objective of this study also identifies the degree of influence and impact of major stakeholders on project planning and execution phase based on questionnaires.

\section{Literature Review}

Different scholars across the globe have studied the identification of key stakeholders from different perspectives. The significant problem for the project management team is to identify and analyses those stakeholders that can influence the decisions of projects (Olander and Landin, 2005). This facilitates managing a process that maximizes stakeholder positive input and minimizes any detrimental or negative impact (Bourne and Walker, 2005). There is a dissimilarity between the stakeholders and influencers. Some performers in association may have impact and a stake and few may only have a stake in the association, while others may have impact only. Such performers that are impacting in associations are characterized as influencers. They represent the media as ordinary influencers, and therefore not act as stakeholder (Donaldson and Preston, 1995). Olander and Landin (2005) additionally characterize that the media is unable to act as stakeholder because of no stake in the association / project. Such point of view is enigmatic issue since it is apparent that media can tremendously affect the organization and venture activities.

Briner, Hastings and Geddes (1996) distinguish four sets of stakeholders' such as project leader's association, clients, indistinguishable team members and outsider services. This point of view on undertaking stakeholders mainly relates with Project Management Institute (2008) and Walker (2003). Conversely, Tuman's methodology (2006) is to recognize project stakeholders to mainly consider four fundamental groups such as participant and victors of projects, community and dependent nature of project. The participants of project among these mainly includes individuals 
who can bring the project into execution. For e.g. the investors, client customers and developers. The participants of project are mainly accountable for preparation and implementation of project; e.g., team of project, employees, constructors and engineers. On the other hand, the communication participants mainly include the groups or individuals who are directly affected by project; e.g., the natural, economic and social environment where the project is executed. Lastly, the individuals and groups who are mainly the family and media those have an indirect stake in project but to present the challenges and are considered as dependent members of project. Various researchers have shared the view that project stockholders are divided into two noteworthy classifications such as external and internal (Calvert, 1995; Mitroff, 1983; Pinto, 1996; and, Winch, 2004).

Pinto (1996) stated that internal stakeholders mainly incorporate the accountants, top and functional management and the team participants of project. The outside stakeholders are suppliers, competitors, clients, political, consumer and environmental groups. Depending upon the linkages between project and its stakeholders; the stakeholders are sorted as primary or secondary (Clarkson, 1995; McElroy and Mills, 2000) and direct and indirect participants of project (Lester, 2007). To some degree, the two techniques basically classify project stakeholders in the same way. In line with Cleland and Ireland (2007), stakeholders that are direct in nature mainly incorporate the individuals who have legitimate associations with the project and a duty in process of project management; e.g., time, cost and management of quality. Likewise, direct stakeholders are individuals that can straightforwardly participate in the arranging, executing and administration procedures of project (Lester, 2007). Both Cleland and Ireland (2007) and Lester (2007) concur that auxiliary and backhanded partners don't take an interest specifically in the venture. Incorporated into this class are ecological, social and financial gatherings, media, and families. Cleland and Ireland (2007) and Lester (2007) stated that direct and indirect stakeholders are unable to participate directly in the project which may include the categories of social, environmental, economic, families, and media groups.

Mitchell, Agle and Wood (1997) address an enigmatic issue regarding influencers that have no claims of legitimacy or possibly any claims at all whatsoever, they do have control over an association or project. The legitimacy and power are dissimilar and occasionally the covering dimensions; so, that theory of stakeholder identification must put up such alterations. In addition, this study further defines the legitimacy and power as essential features in a complete stakeholder identification model and includes a dynamic attribute of urgency to finalize that model. The stakeholder's classes can be distinguished by their ownership of one, two or three attributes such as the power of stakeholders to influence, the linkages of stakeholders 
regarding legitimacy and the urgency of stakeholders. Along these lines, the stakeholders of project can be characterized as peoples / groups of peoples who have a personal stake in the achievement of a task and nature inside which the project mainly executes. The vested interest is characterized as having ownership of at least one of the partner characteristics of legitimacy, power or urgency. There are basically two classes of stakeholders such as inside and outside stakeholders. The inside stakeholders are those who effectively engage with execution of project; and outside stakeholders are those influenced by project. The seven classes of stakeholder which are dependent on distribution of attributes regarding stakeholders i.e. dormant (P), discretionary $(\mathrm{L})$, demanding $(\mathrm{U})$, dominant $(\mathrm{P}+\mathrm{L})$, dangerous $(\mathrm{P}+\mathrm{U})$, dependent $(\mathrm{L}+\mathrm{U})$ and definitive stakeholders $(\mathrm{P}+\mathrm{L}+\mathrm{U})$.

Olander (2007) studied the Stakeholder Impact Analysis (SIA) in construction project management. The projects of construction sector can attract more interest from many stakeholders who express expectations and needs about the project. These are often in conflict with each other and it is unlikely that all of them can be fulfilled. The process of stakeholder's management mainly involves assessing the expectations and needs of stakeholders in relation to main aims of project. The significant basis for such evaluation is stakeholder analysis. The method is based on established theory, stakeholder's knowledge and empirical data. The analysis consists of a Stakeholder Impact Index (SII) to find the nature and impact of stakeholder influence, the probability of stakeholders exercising their influence and position of each stakeholders in terms of the project where they are opponents / proponents? Overall, the result reveals that the analysis of SII can assist the project managers to formalize the process of stakeholder's management.

Nguyen, Skitmore and Wong (2009) studied the SIA regarding the project management of infrastructure sector in Vietnam. The study is composed of the valuable thoughts of the project managers of the state companies. According to the study, the success of the construction project depends upon fulfilling the expectations of the diverse stakeholders. A SIA based on a method established by Olander (2007), was adopted to investigate the stakeholders' impact on the state-owned civil engineering projects. The methodology is based on questionnaire by using 57 project managers. The results reveal that the client has the highest level of impact on projects, followed by project managers and the senior management of state-owned engineering firms. The SIA also offers recommendations to project managers in developing and evaluating the process of stakeholder management.

Malkat and Byung-Gyoo (2012) investigated the stakeholders in construction projects of Dubai and adjacent regions. The management of shareholders in construction sectors is a relatively new idea in Dubai and adjacent regions. The methodology is based on online survey questionnaire 
that was mailed to construction professionals. The data collected was statistically analyzed based on sample size of 77 respondents. Salient stakeholder is defined using the attributes; legitimacy, power and urgency. The result reveals that salient stakeholder is the project manager. The satisfaction of client must be sustained during the PLC. The paradoxical finding is that client is perceived as the powerful stakeholder, they are not the party who imposes maximum influence on project spheres. The professional of construction sector can essentially use result of research in a better way to implement the management of stakeholders. Overall, the linkages between stakeholder's attribute, power and influence sphere is because of improved understanding.

Assefa, Worke and Mohammed (2015) studied the SIA on the projects regarding management of road construction in Ethiopia. The management of stakeholder is one of the most crucial parts of project management. The disagreement and changes in project features of project are budget, time and design at the time of construction. Furthermore, the effect and poor participation mostly occurred in road construction projects in Ethiopia. The aim of their study is to evaluate the impact of external and internal stakeholders on road construction projects in the western region of Ethiopia Road Authority. The methodology is based on interviews and questionnaire. The result reveals that out of 6-current projects, in which one project has no change in design while the other five face design changes because of the influence of external stakeholders. The participants specify some reasons which poor engagement between project undertaking parties and external stakeholders and less budget, time and consideration are given at design stage from client side.

\section{Data and Methodology}

\subsection{Data}

The primary data used in this qualitative research to investigate the management and evaluation of communication and coordination practices among multi stakeholders in complex engineering projects in Pakistan.

\subsection{Research Software}

The software used in current study is MS-Excel 2016.

\subsection{Sample Size}

There are 80 respondents used in past work to investigate the SIA regarding management of infrastructure projects in Vietnam (Nguyen et al., 2009). The current study used 200 questionnaires' in which 132 responses were received. Thus, sample size of the current study is 132 respondents. The Table 3.1 shows the list of selected key stakeholders. 


\begin{tabular}{|c|l|c|}
\hline S. No. & \multicolumn{1}{|c|}{ Stakeholders } & Qty \\
\hline 1 & Client & 32 \\
\hline 2 & Consultants & 32 \\
\hline 3 & Main Contractor & 13 \\
\hline 4 & Sub-Contractor & 09 \\
\hline 5 & Government Agencies & 05 \\
\hline 6 & Politicians & 05 \\
\hline 7 & Media & 05 \\
\hline 8 & Institutional Forces/NGOs & 05 \\
\hline 9 & Local Community/ Residents & 05 \\
\hline 10 & Land Owner & 10 \\
\hline 11 & Environmentalist & 06 \\
\hline & & $\mathbf{1 3 2}$ \\
\hline
\end{tabular}

Table 3-1 List of Key Stakeholders

It is clear from above table 3.1, that the internal stakeholders are clients, consultants, main consultant and sub-contractors which are 86 while the remaining 46 respondents are external stakeholders.

\subsection{Methodology}

The methodology of the current study is based on questionaries' to calculate ViII, Pos, A and SII to analyze the stakeholders impact in construction project management (Oleander, 2007; Nguyen et al., 2009). There are some other studies who find the normalize score of SII and ranking of normalize score of SII of all stakeholders (Ho, 2006; Ho and Wu, 2006). This study also used the Stakeholder Impact/ Probability matrix (Olander, 2007). The questionaries' consist of three parts. The part-A contains 2 sections. The section 1 and 2 contains; 11 questions each for vested interest levels (v) and influence impact levels (i), respectively. The part-B includes 11 questions to determine the position of selected stakeholders in complex projects while part-C also contains 11 questions to determine the prevailing attributes of selected stakeholders in complex projects. The total of 44 questions are asked from 132 stakeholders regrading project's planning and execution phase.

\subsection{Variables Measurement and Definitions}

\subsubsection{Vested Interest-Impact Index (ViII)}

Bourne and Walker (2005b) establish a connection between the interest/impact and the concepts resulting from the risk assessment process associated with probability-impact analysis. Such method is reasonable because, to some extent, stakeholders can be considered as project risks (including threats and opportunities). They suggest a scale for measuring stakeholder vested interest (v) and impact (i) as 1- very low, 2-low, 3-neutral, 
4-high, and 5-very high. The Vill is calculated as under (Bourne and Walker 2005b; Olander, 2007; Nguyen et al., 2009).

Vill $=\sqrt{\frac{v * i}{25}}$

Where,

$\mathrm{v}=$ The stakeholders vested interest levels

$\mathrm{i}=$ The stakeholders impact levels

\subsubsection{Position Value (Pos)}

Stakeholders may have negative / positive impacts on projects. There is a need to find the supports and complainers. Stakeholder attitude mainly refers to whether stakeholder supports / opposes the project (McElroy and Mills, 2000; Nguyen et al., 2009). In other words, this factor gives a 'clue' for managers to be aware that stakeholders have positive / negative influences on results of project. In line with McElroy and Mills (2000) who have used Pos on a scale of five from -1 to 1 , which are given as under;

Pos $=-1$ (Active Opposition)

Pos $=-0.5$ (Passive Opposition)

Pos $=0$ (Not Committed)

Pos $=0.5$ (Passive Support)

Pos $=1$ (Active Support)

\subsubsection{Stakeholder Attribute Value (A)}

It is measured by weighing 3-attribute such as legitimacy, power, urgency or power; where these are given a weight between 0 and 1, with the total sum of the attribute weights as 1 . The stakeholder attribute value depends on the distribution of these 3- attributes in which every stakeholder keeps and views their comparative strength with respect to project. These distributions of weights vary from project to project. In this research, the weights have been determined as $\mathrm{p}=0.4, \mathrm{l}=0.3$ and $\mathrm{u}=0.3$ (Olander, 2007)

\subsubsection{Stakeholder Impact Index (SII)}

Bourne and Walker (2005) put forward two parameters to present the vested interest index: vested interest levels that influence impact level which then, predominantly defines the probability and level of stakeholder's impact. Nevertheless, for a detailed stakeholder analysis the nature of the impact needs to be unified. Hence, the addition of the two concepts achieves: the trait value based on investor classes (Mitchell et al., 1997) and the position value based on the levels of investor position proposed by (McElory and Mills, 2000). The project managers can calculate the SII by multiplying the ViII, Pos and A (Olander, 2007). 
SII $=$ Vill $*$ Pos $* A$

\subsubsection{Normalize Score of SII}

The SII are normalized based on formula given in equation 3.3 which is used to rank normalize score of SII based on calculated value of Vill, Pos, A and SII. Therefore, normalization of SII are concentrating on using original value of measures and then taking square root of the summation of unique indicator values which is shown in below (Ho, 2006; Ho and Wu, 2006).

Where,

$$
r_{i j}=\frac{x_{i j}}{\sqrt{\sum_{i=1}^{m} x_{i j}^{2}}}
$$

$\mathrm{i}=$ The $\mathrm{i}^{\text {th }}$ shareholders

$\mathrm{j}=$ The $\mathrm{j}^{\text {th }}$ measures

$\mathrm{r}_{\mathrm{ij}}=$ The value of performance regarding stakeholders after normalization of data for

magnitude and direction

$\mathrm{x}_{\mathrm{ij}}=$ The unique performance value of stakeholders

$\mathrm{m}=$ The no. of stakeholders

\section{Results and Discussions}

The result of planning and execution phase is shown in Table 4.1 which includes combination of feasibility, inception and detailed design phase. The results of key stakeholders' class, ViII, Pos, A, SII, normalize score of SII and rank of normalize score of SII are shown in Table 4-1 and the Stakeholder Impact/Probability matrix showing what action of coordination is required at PP and EP is shown in Appendix-I, Figure 4.1 and 4.2, respectively.

\subsection{Internal Stakeholder}

It is clear from Table 4.1 that class of client is Dominant in planning and execution phases as they exhibit both power and legitimacy. The client's impact is 0.4292 on the project, showing that they have strong favorable (positive) impact on the project's PP. Being the owner/sponsor of the project, there influence on the project is higher as compared to other stakeholders and ranked on top as shown in Table 4.1. In EP phase, the impact of 0.4435 on the project is observed which shows that they have favorable (positive) impact on the project execution phase and ranked on top. The influence level reduces from 0.4292 to 0.4435 which signify that more risks are involved in Project's EP as compared to Project's PP. 
The class of consultant is Dependent in planning and execution phases as they as they exhibit both urgency and legitimacy. At PP the consultant must design as per the requirement of the client, hence it depends solely on client. The consultant's impact is 0.3875 on the project showing that they have second most favorable (positive) impact on the project's PP. The consultant brings into form the concept of client and is therefore dependent on client's demand. In EP phase, the consultant must supervise as per the design and specification requirement of the project, hence the consultant ensures that the contractor performs accordingly. The consultant's impact is 0.4110 on the project showing that they exhibit second most favorable (positive) impact on the project during EP. The class of main contractor in planning and execution phases is Discretionary as they exhibit legitimacy only. The impact of main contractor is 0.3075 on the project showing that the main contractor is ranked third and have a favorable (positive) impact on the project's PP. The impact in execution phase is 0.3704 on the project showing that the main contractor has third most favorable (positive) impact on the project's EP because main execution tasks must be performed by contractor on ground. More risk is always involved during execution as compared to project's PP.

The class of sub-contractor in planning and execution phase is Discretionary as they exhibit legitimacy only. The sub-contractor has a favorable (positive) impact on project's PP which is 0.1897 and ranked fourth among all stakeholders. However, their inputs are only required by some consultant or client to prepare bill of quantities or if some innovation is to be introduced in project's PP that's why ranked second. In execution phase, the sub-contractors must perform different tasks/activities of project assigned by main contractor. Their impact is 0.2345 on the project showing that the subcontractor has high and favorable (positive) impact on the project EP and ranked on fifth in project's EP. The risk level of sub-contractor is greater than EP as compared to PP. The Stakeholder Impact/Probability matrix shows that $\mathrm{SC}$ falls in keep informed quadrant.

\subsection{External Stakeholders}

It is clear from Table 4.1 that the class of government agencies is Dominant in planning and execution phase as they exhibit both power and legitimacy. Their impact is 0.2316 on the project showing that they have slightly low but favorable (positive) impact on the project's PP and ranked on fifth. The Stakeholder Impact/Probability matrix shows that government agencies fall in manage closely and act as key players in planning phase. Their favorable impact helps the client to bring his concept into form. Disbursement of funds and negotiations regarding rates of land with land owners are done during PP. The normalize score is 0.2642 on the project showing that government agencies have favorable (positive) impact on the project EP and 
ranked fourth as compared to other stakeholders. Government agencies whose utilities come across the project area must be re-located during execution or project area must be re-shifted because of that. The Stakeholder Impact/Probability matrix shows that government agencies are the key players in EP and to be managed closely all the time therefore strong and effective communication with efficient coordination is required.

The class of politicians is Dangerous as they exhibit in planning and execution phase both power and urgency. Their impact is negative i.e. -0.1100 on the project showing that they have highest and unfavorable (negative) impact on the project's PP. The Stakeholder Impact/Probability matrix shows that politicians are managed closely and kept informed all the time that leads to good coordination and effective communication is required. The impact of politician on project's execution phase is -0.1299 which shows that they have unfavorable (negative) impact on the project EP and ranked on seventh. The Stakeholder Impact/Probability matrix shows that politicians must be kept informed and managed closely therefore good coordination and effective communication is required. Dangerous stakeholders are always a threat to the project.

The class of media is Demanding in planning and execution phase as they exhibit urgency only. Their impact is -0.2830 on the project showing that they have unfavorable (negative) impact on the project's PP and ranked ninth. The Stakeholder Impact/Probability matrix shows that media are kept informed all the time therefore effective communication is mandatory that will lead to favorable impact on project's PP. The impact of media on project's execution phase is -0.1622 which shows that they have unfavorable (negative) impact on the project's EP and ranked eleven. The Stakeholder Impact/Probability matrix shows that media must be kept informed and managed closely all the time therefore good and effective communication is required. If not managed properly they can propagate negative image of the project which might create doubts in the mind of public regarding the project.

The class of institutional forces / NGOs is Demanding like media in planning and execution phase as they exhibit urgency only. Their impact is 0.1396 on the project showing that they have unfavorable (negative) impact on the project's PP. Their role is to compete against the project if it harms the environment, culture, heritage etc. in the vicinity. The Stakeholder Impact/Probability matrix shows unlike media less effort of $\mathrm{C} \& \mathrm{C}$ is required as their influence is slightly less i.e. -0.1269 and ranked eight with lower impact as compared to media. The impact of institutional forces / NGOs is 0.1285 in project execution phase which shows that they have unfavorable (negative) impact on the project EP and ranked as eight as compared to other stakeholders. The Stakeholder Impact/Probability matrix shows that institutional forces / NGOs 


\begin{tabular}{|c|c|c|c|c|c|c|c|c|c|c|c|c|c|c|}
\hline \multirow{2}{*}{ Stakeholder } & \multicolumn{7}{|c|}{ Planning Phase } & \multicolumn{7}{|c|}{ Execution Phase } \\
\hline & Class & Vill & Pos & A & SII & $\begin{array}{c}\text { Normalize } \\
\text { Score }\end{array}$ & Rank & Class & Vill & Pos & A & SII & $\begin{array}{c}\text { Normalize } \\
\text { Score }\end{array}$ & Rank \\
\hline Client & Dominant & 0.6784 & 0.7159 & 4.6591 & 2.2628 & 0.4292 & 1 & Dominant & 0.7071 & 0.7159 & 4.6591 & 2.3584 & 0.4435 & 1 \\
\hline Consultant & Dependent & 0.6616 & 0.6534 & 3.8722 & 1.6740 & 0.3875 & 2 & Dependent & 0.7111 & 0.6534 & 3.8722 & 1.7991 & 0.4110 & 2 \\
\hline Main Contractor & Discretionary & 0.5317 & 0.6224 & 3.7063 & 1.2264 & 0.3075 & 3 & Discretionary & 0.6597 & 0.6224 & 3.7063 & 1.5218 & 0.3704 & 3 \\
\hline Sub. Contractor & Discretionary & 0.4502 & 0.4343 & 4.0000 & 0.7821 & 0.1897 & 5 & Discretionary & 0.5642 & 0.4343 & 4.0000 & 0.9803 & 0.2345 & 5 \\
\hline Government Agencies & Dominant & 0.6511 & 0.3727 & 3.8000 & 0.9222 & 0.2316 & 4 & Dominant & 0.7527 & 0.3727 & 3.8000 & 1.0661 & 0.2642 & 4 \\
\hline Politicians & Dangerous & 0.6502 & -0.1727 & 3.9455 & -0.4431 & -0.1100 & 7 & Dangerous & 0.7739 & -0.1727 & 3.9455 & -0.5274 & -0.1299 & 8 \\
\hline Media & Demanding & 0.6064 & -0.2364 & 3.5636 & -0.5108 & -0.1396 & 9 & Demanding & 0.7106 & -0.2364 & 3.5636 & -0.5986 & -0.1622 & 9 \\
\hline Institutional Forces/NGOs & Demanding & 0.4584 & -0.2818 & 3.8364 & -0.4956 & -0.1269 & 8 & Demanding & 0.4644 & -0.2818 & 3.8364 & -0.5021 & -0.1285 & 7 \\
\hline Local Community/Residents & Dependent & 0.5865 & -0.3682 & 3.2727 & -0.7068 & -0.2067 & 10 & Dependent & 0.6918 & -0.3682 & 3.2727 & -0.8336 & -0.2404 & 10 \\
\hline
\end{tabular}

Table 4.1: Comparison of Results Between Planning and Execution Phase

falls in minimal efforts quadrant regarding project's EP all the time, otherwise their unfavorable impact creates hurdles in execution of project. The class of local community/ Residents is Dependent in planning and execution phase as they exhibit both urgency and legitimacy. Their impact is -0.2067 on the project showing that they have unfavorable (negative) impact on the project's PP and ranked tenth. The Stakeholder Impact/Probability matrix shows that local community/ residents fall in keep satisfied quadrant which signify that they are well informed all the time therefore good and effective communication is mandatory. If not informed properly regarding project, their opposition can increase time or cost overrun of the project's PP and lead to unfavorable (negative) impact. The impact is -0.2404 in project's execution phase which shows that they have unfavorable (negative) impact on the project EP. The Stakeholder Impact/Probability matrix shows that local community / residents are key players and must be kept informed regarding project all the time, otherwise their unfavorable impact create hurdles in execution of project. Therefore, good and effective communication is required to increase their low impact on project's EP.

The result shows that for PP the class of land owners is Dominant as they exhibit power, urgency and legitimacy. They have -0.2903 impacts on the project showing that they have unfavorable (negative) impact on the project's PP and ranked eleventh. The Stakeholder Impact/Probability matrix shows that land owners falls in manage closely and consider as key players and therefore 
high-quality coordination and effective / strong communication is required all the time. Due to their negative influence they are watched by client and other government agencies because such external stakeholders must be kept informed as per the Stakeholder Impact/Probability matrix.

The result shows that for EP the class of land owners is Definitive in planning and execution phase as they as they exhibit power, urgency and legitimacy. Their impact is -0.2765 on the project showing that they have unfavorable (negative) impact on the project EP and ranked ninth. The less risk is observed during EP as compared to PP. The Stakeholder Impact/Probability matrix shows that land owners must be kept informed and must be managed very closely therefore high-quality coordination and effective / strong communication is required all the time and to increase its impact on EP.

The result shows that for PP the class of environmentalists is Dominant in planning and execution phase as they exhibit both power and legitimacy. They have -000716 of impact on the project showing that they have unfavorable (negative) impact on the project's PP and ranked sixth. The Stakeholder Impact/Probability matrix shows that environmentalists are kept informed for the purpose to manage closely and efficient communication. Without prior approval from environmentalists the project cannot be executed. The impact of environmentalist is -0.0540 on the project's EP showing that they have unfavorable (negative) impact on the project EP. The Stakeholder Impact/Probability matrix shows that environmentalist falls in minimal efforts quadrant therefore less coordination is needed that's why ranked on sixth shown in Table 4.1.

\section{Conclusions}

The objectives of this research study were to identify management practices of $\mathrm{C} \& \mathrm{C}$ among stakeholders in complex projects and their implications during two phases (planning and execution), and to suggest measures for its improvement. Based on the study results, the conclusions are drawn, and recommendations are made based on extensive literature review and interview survey selected for both phases. The date was collected from all key stakeholders. The study results reveal that internal stakeholders in both phases of project have positive impact on the project whereas external stakeholders other than government agencies have negative impact on the project. To cater for this impact high coordination and effective communication is required. For internal stakeholder, client has the most positive impact followed by consultant and main contractor respectively. The class of client remains Dominant in both phases whereas class of consultant also remains same as Dependent. For external stakeholder, land owner has the most negative impact throughout the project followed by local community, media, institutional forces/ NGOs and politicians, respectively. The class of 
all external stakeholders are same in both phases shown in Table 4.1. The ranking of normalize score based on SII shows that clients are on top in both phases while media is on eight in Project's PP while eleventh on project's EP. The ranking of politician is on seventh. It is clear from Table 4.1 that the top five stakeholders are clients, consultants, main contractors, sub-contractors and government agencies in project's PP and project's EP. Overall the result shows that since there is no contractual binding between external stakeholders and project sponsor, they face the maximum communication gap. There is no proper mean to establish coordination and communication among external stakeholders throughout the project.

\subsection{Recommendations}

There are few recommendations that will enhance efficiency of communication and coordination among stakeholders in future and reduce their negative impact in complex projects of Pakistan which are given as under:

a. Proper framework of communication and coordination for external stakeholders must be developed in accordance with their class at each phase of project.

b. Key stakeholders that exhibit strong positive impact on the project such as client, consultant, sub-contractors, main contractors and government agencies should utilize their impact to reduce the negative impact of other key stakeholders like land owners, environmentalists, media, politicians, institutional forces/NGOs and local community/residents.

c. For land owner, the structure of land should be compensated based on present construction cost of similar project, rather than net present value of the project.

d. The land should be compensated above the market value keeping in view availability of land in similar location in case of shop keepers.

e. Land owners as well as other key stakeholders like politician, local community/ resident and institutional forces/NGOs should be considered in planning phase. Their suggestions, needs and requirements must be considered.

f. Special committee must be established for communication and coordination with dangerous, depending, definitive, depending, demanding class stakeholders having negative impact on project.

g. Land owners should be given free consultancy service and other departmental fees may be waved off. 


\section{References:}

1. Assefa, S., Worke, Z. T., \& Mohammed, M. (2015). Stakeholders Impact analysis on road construction project management in Ethiopia: A case of Western region. International Journal of Engineering and Technical Research, 3(11),115-121.

2. Bourne, L., \& Walker, D. H. (2005). Visualizing and mapping stakeholder influence. Management decision, 43(5), 649-660.

3. Briner, W., Hastings, C., \& Geddes, M. (1996). Project leadership. Aldershot, UK, Gower.

4. Calvert, S. (1995), Managing Stakeholders. In the commercial project manager: Managing owners, sponsors, partners, supporters, stakeholders, contractors and consultants, ed. J.R. Turner. London; New York: McGraw-Hill.

5. Clarkson, M.B.E. (1995), A stakeholder framework for analyzing and evaluating corporate social performance, The Academy of Management Review, 20(1), 92-117.

6. Cohen, B. (2006). Urbanization in developing countries: Current trends, future projections, and key challenges for sustainability. Technology in Society, 28(1), 63-80.

7. Donaldson, T., \& Preston, L. E. (1995). The stakeholder theory of the corporation: Concepts, evidence, and implications. Academy of management review, 20(1), 65-91.

8. Freeman, R. (1984). Strategic management: A stakeholder approach. Pitman, Boston, freeman Re (1994) The politics of stakeholder theory: Some future directions. Business Ethics Q, 4(4), 409-421.

9. Hossain, L. (2009). Communications and coordination in construction projects. Construction Management and Economics, 27(1), 25-39.

10. Project Management Institute (2008). A guide to the project management body of knowledge.

11. Khan, R. A. (2008). Role of construction sector in economic growth: empirical evidence from Pakistan economy. Paper presented at the proceedings of the first International Conference on Construction in Developing Countries, Karachi, Pakistan.

12. Malkat, M., \& Byung-Gyoo, K. (2012). An investigation on the stakeholders of construction projects in Dubai and adjacent regions. International Proceedings of Economics Development \& Research, 45(1), 77-82.

13. Mcelroy, B., \& Mills, C. (2000). Managing stakeholders. Gower handbook of project management, 757-775.

14. Meng, X. (2012). The effect of relationship management on project performance in construction. International journal of project management, 30(2), 188-198. 
15. Mitchell, R. K., Agle, B. R., \& Wood, D. J. (1997). Toward a theory of stakeholder identification and salience: Defining the principle of who and what really counts. Academy of management review, 22(4), 853-886.

16. Mitroff, I.I. (1983). Stakeholders of the organizational mind. San Francisco: Jossey-Bass.

17. Nguyen, N. H., Skitmore, M., \& Wong, J. K. W. (2009). Stakeholder impact analysis of infrastructure project management in developing countries: A study of perception of project managers in state-owned engineering firms in Vietnam. Construction Management and Economics, 27(11), 1129-1140.

18. Olander, S. (2002). Consensual approaches to siting controversy. Paper presented at the Organization and Management of Construction, 10th International Symposium, Construction Innovation and Global Competitiveness.

19. Olander, S. (2007). Stakeholder impact analysis in construction project. Construction Management and Economics, 25(3), 277-287.

20. Olander, S., \& Landin, A. (2005). Evaluation of stakeholder influence in the implementation of construction projects. International journal of project management, 23(4), 321-328.

21. Pinto, J.K. (1996). Power and politic. Project Management Institute (PMI).

22. Ward, S., \& Chapman, C. (2003). Transforming project risk management into project uncertainty management. International Journal of Project Management, 21(2), 97-105.

23. Watson, T., Osborne-Brown, S., \& Longhurst, M. (2002). Issues negotiation ${ }^{\mathrm{TM}}$-investing in stakeholders. Corporate Communications: An International Journal, 7(1), 54-61.

24. Winch, G.M. (2004). Managing stakeholders. In the wiley guide to managing projects, ed. P.W.G. Morris and J.K. Pinto, John Wiley \& Sons, Hoboken, New Jersey. 321-339 


\section{Appendix-I:}

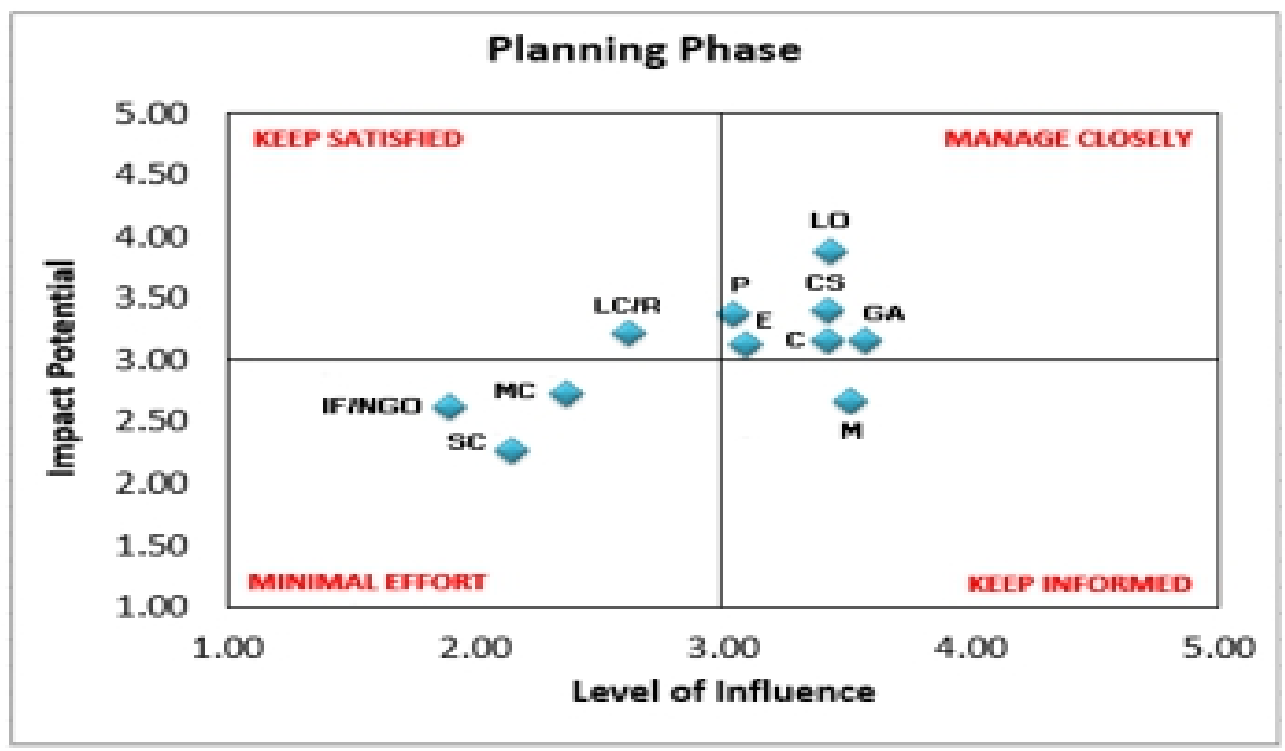

Figure 4.1 Stakeholder Impact / Probability Matrix

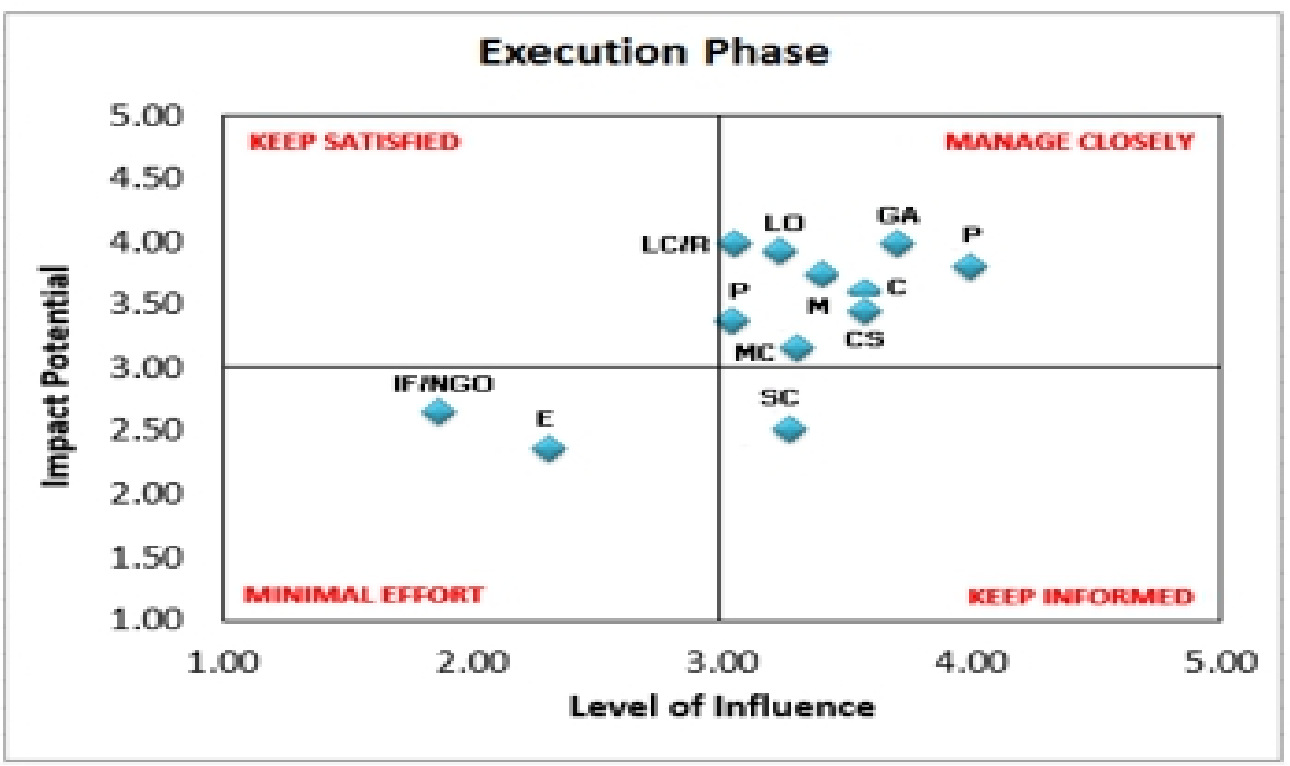

Figure 4.2 Stakeholder Impact / Probability Matrix 